\title{
Emissões otoacústicas no diagnóstico precoce de lesão coclear na doença de Ménière
}

\section{Otoacoustic emissions in early diagnosis of cochlear lesions in Ménière's disease}

Antonio M. C. M. Aquino ${ }^{1}$, Carolina A. M. Massaro ${ }^{2}$, Juliana B. Tiradentes ${ }^{3}$, Juan C. V. Garzón ${ }^{4}$, José A. A. Oliveira ${ }^{5}$

\section{Resumo / Summary}

$\mathbf{N}$ flutuante predominante em baixas frequências e também alterações nas otoemissões acústicas (EOA) nas freqüências correspondentes àquelas da flutuação, que não são correlacionadas aos limiares auditivos encontrados na audiometria tonal. Estas alterações, experimentalmente, não estão relacionadas à perda de células ciliadas externas (CCE) no ápice coclear, sendo que suas causas ainda não são muito claras podendo ser atribuídas às alterações do micromecanismo hidrodinâmico e biomecânico coclear. Assim, as EOA mostraram, neste caso apresentado, alterações cocleares na Doença de Ménière compensada em fase inicial que ainda não são detectadas no audiometria tonal e exames convencionais, sendo portanto um exame que pode mostrar lesão precoce por alteração apenas do micromecanismo coclear.

\author{
Palavras-chave: Ménière, emissão otoacústica, \\ cóclea, hipertensão endolinfática. \\ Key words: Ménière, otoacoustic emission, \\ cochlea, endolymphatic hypertension.
}

\begin{abstract}
F ofuting deafness predominating in low frequencies can occur in the early phase of Ménière disease, together with changes in otoacoustic emissions (OAE) at the frequencies corresponding to the fluctuating ones, which are not correlated with the auditory thresholds detected in tone audiometry. In experimental studies, these changes are not related to the loss of outer hair cells (OHC) in the cochlear apex and their cause is still unclear, possibly corresponding to alterations in the hydrodynamic and biomechanical micromechanism of the cochlea. The OAE observed in the present case showed cochlear alterations in the early compensated phase of Ménière disease which cannot be detected by tone audiometry or standard examinations. Thus, this examination can reveal early lesions due to alterations of the cochlear micromechanism only.
\end{abstract}

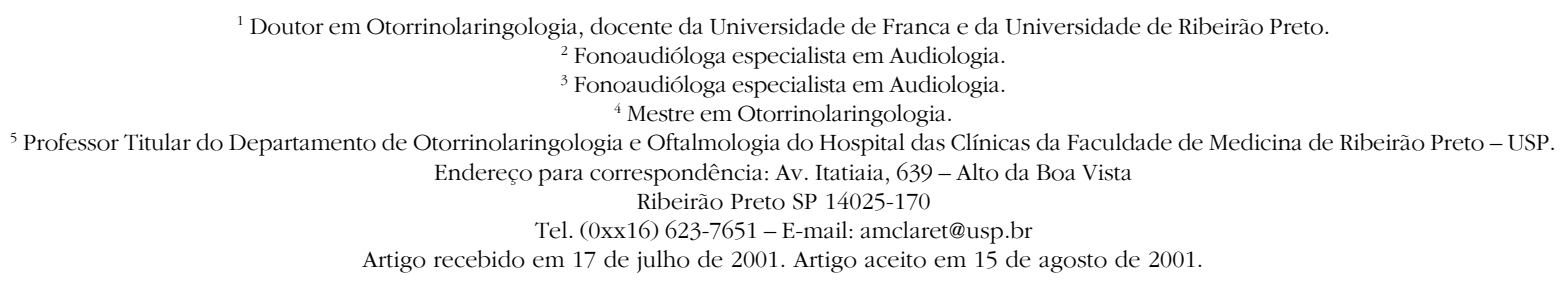

Revista Brasileira de Otorrinolaringologia 68 (5) Parte 1 Setembro/Outubro 2002

http://www.sborl.org.br / e-mail: revista@sborl.org.br 


\section{INTRODUÇÃO}

As emissões otoacústicas foram primeiramente observadas pelo inglês David Kemp, em 1978, que as definiu como liberação de energia sonora originada na cóclea, que se propaga pela orelha média até alcançar o conduto auditivo externo. Ele demonstrou que as EOA estão presentes em todos as orelhas funcionalmente normais e que deixam de ser detectadas quando os limiares tonais estão acima de 2030 dB (Kemp et al., 1986).

As EOA são sons subliminares detectados no conduto auditivo externo e gerados pela célula ciliada externa, sendo um exame indicado no diagnóstico de diversas cocleopatias, inclusive na doença de Ménière. Tem sido muito útil em triagem auditiva de crianças de alto risco em berçários, como exame complementar ao BERA no topodiagnóstico de patologias retrococleares, e em pesquisas. $\mathrm{O}$ exame tem uma duração de aproximadamente três minutos para a testagem de ambas as orelhas. É uma técnica promissora para o diagnóstico auditivo por ser simples, rápida e não invasiva (Isaac e Aquino, 1998).

O recente descobrimento das EOA contribuiu substancialmente para a formação de novo conceito sobre a fisiologia da cóclea, mostrando que esta não é só capaz de receber sons, mas também de produzir energia acústica através do processo eletrobiomecânico ativo coclear. Este fenômeno vem sendo recentemente atribuído a contrações rápidas e lentas das células ciliadas externas e é controlada através das vias auditivas eferentes (Oliveira, 1997).

As emissões otoacústicas são consideradas um instrumento clínico para monitorar a função coclear. Há evidências de que pequenas alterações do funcionamento coclear podem ser detectadas pelas emissões otoacústicas antes mesmo de apresentar qualquer mudança no audiograma (Carnicelli, 1997). O limiar de detecção das otoemissões chega a ser mais baixo que o limiar subjetivo em aproximadamente $10 \mathrm{~dB}$ (Oliveira, 1997). Assim, as EOA são indicadas no monitoramento da função coclear de curto, médio e longo prazo (Carnicelli, 1997).

Sendo um método mais sensível que a audiometria tonal, a monitorização auditiva através das EOA evocadas está indicada na PAIR, ototoxicidade e na doença de Ménière. Na hidropsia endolinfática ou doença de Ménière a presença ou ausência de EOA-Produtos de Distorção (EOA-PD) ajudam a estabelecer se a doença está compensada (com perda auditiva flutuante) ou descompensada (perda auditiva definitiva) (Lopes Filho et al., 1997).

Pacientes com a doença de Ménière apresentam sintomas relacionados ao envolvimento dos sistemas vestibular e auditivo. Embora várias teorias tenham sido propostas para explicar as mudanças de sensitividade nesta doença, as alterações cocleares responsáveis ainda não foram determinadas definitivamente. A teoria dominante nas pesquisas sobre a doença de Ménière é que ela é causada pelo aumento de pressão devido ao acúmulo de endolinfa. Esta condição pode ser criada experimentalmente em animais pela obstrução do saco endolinfático, que geralmente ocasiona hidropisia endolinfática, com resultados similares aos encontrados em seres humanos. Entretanto, os mecanismos subjacentes às alterações de sensitividade encontradas experimentalmente também ainda não estão claros (Harris e Probst, 1991).

Alterações rápidas de sensitividade em freqüências graves ocorrem nos primeiros dias da instalação da hidropisia em cobaias, com alterações dos limiares de EOA nas freqüências correspondentes à diminuição de sensitividade. Desde que as células ciliadas não estão destruídas durante os primeiros estágios da doença, os autores propõem que isto ocorra devido a alterações do micromecanismo tanto hidromecânico como biomecânico que afeta a transmissão do estímulo pela célula ciliada externa do órgão de Corti. É provável que muitos fatores sejam responsáveis pelos complexos mecanismos responsáveis pela perda auditiva encontrada na doença de Ménière, apesar de sabermos que o aumento de pressão endolinfática atua direta ou indiretamente sobre a célula ciliada externa, ainda é difícil correlacionar os achados experimentais em animais com os sintomas encontrados em humanos (Horner e Cazals, 1989).

Nosso objetivo é mostrar que na doença de Ménière inicial pode ocorrer surdez flutuante predominante em freqüências graves e também alterações tardias nas EOA nas freqüências correspondentes àquelas da flutuação que não são correlacionadas aos limiares auditivos encontrados na audiometria tonal. Assim, as EOA podem mostrar alterações cocleares precoces na doença de Ménière inicial que ainda não são detectadas na audiometria tonal e exames convencionais.

\section{APRESENTAÇÃO DO CASO CLÍNICO}

N. N., 32 anos, médico, casado, que há 1 ano apresentou quadro de hipoacusia súbita leve, zumbido contínuo de tonalidade grave e plenitude em orelha esquerda, concomitante com tontura rotatória com duração de minutos que pioravam com o movimento da cabeça. O paciente negou uso de medicamentos, exposição prolongada a ruídos, doenças metabólicas, alergias ou sintomas de doenças viróticas nos dias que antecederam o quadro. Nesta época, o exame físico foi normal, com exceção dos testes de Romberg que mostrava látero-pulsão discreta. A audiometria tonal mostrou perda auditiva leve em freqüências graves tipo neurossensorial em ouvido esquerdo. A timpanometria, o reflexo do estapédio e o IRF (Índice de reconhecimento de fala) estavam normais em ambas as orelhas.

Após 10 dias houve total remissão dos sintomas clínicos e também normalização dos limiares tonais, caracterizando uma surdez flutuante típica do doença de Ménière inicial (Figura 1a). 


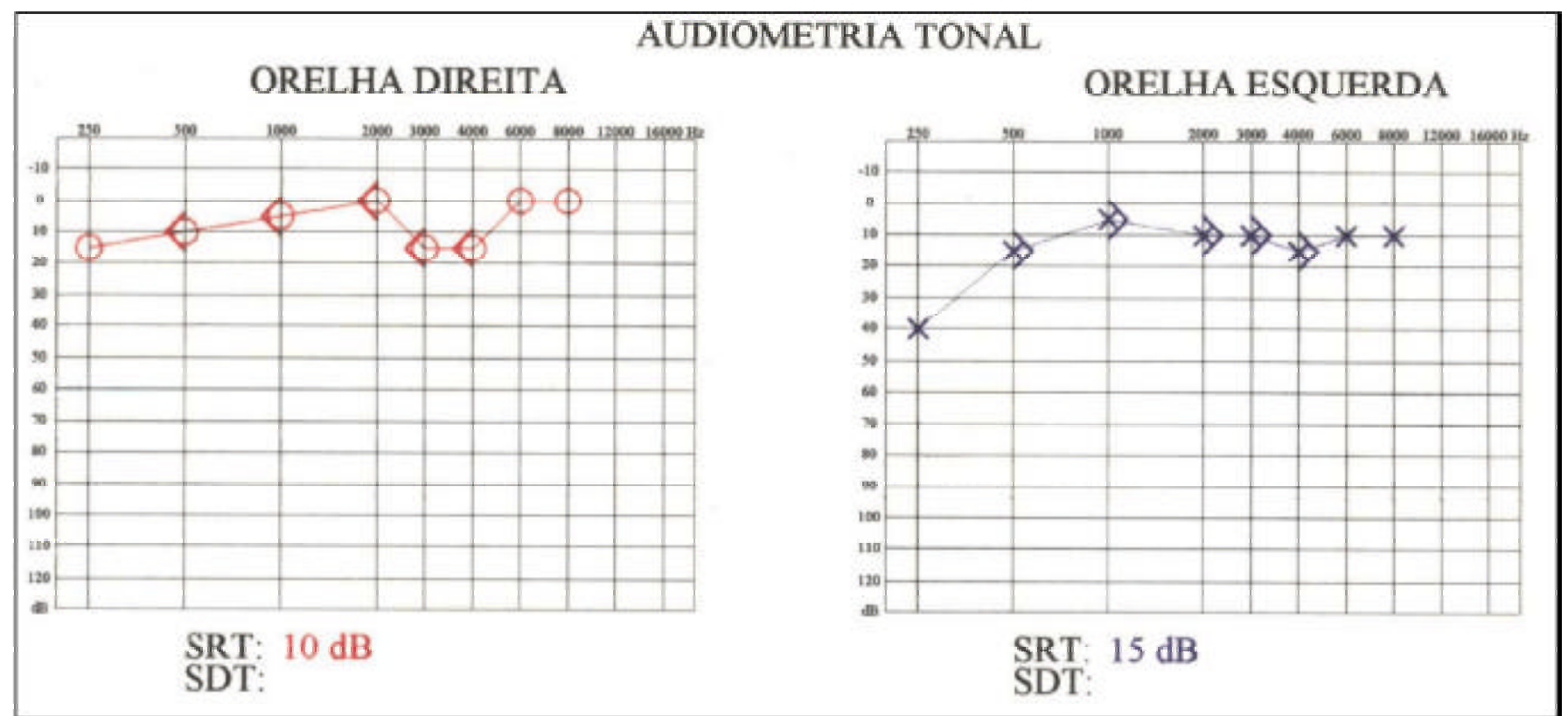

Figura 1a. audiometria tonal realizada durante a crise vertiginosa mostrando perda auditiva em freqüências graves com curva ascendente em orelha esquerda. A imitanciometria, reflexo do estapédio e IRF estavam normais.

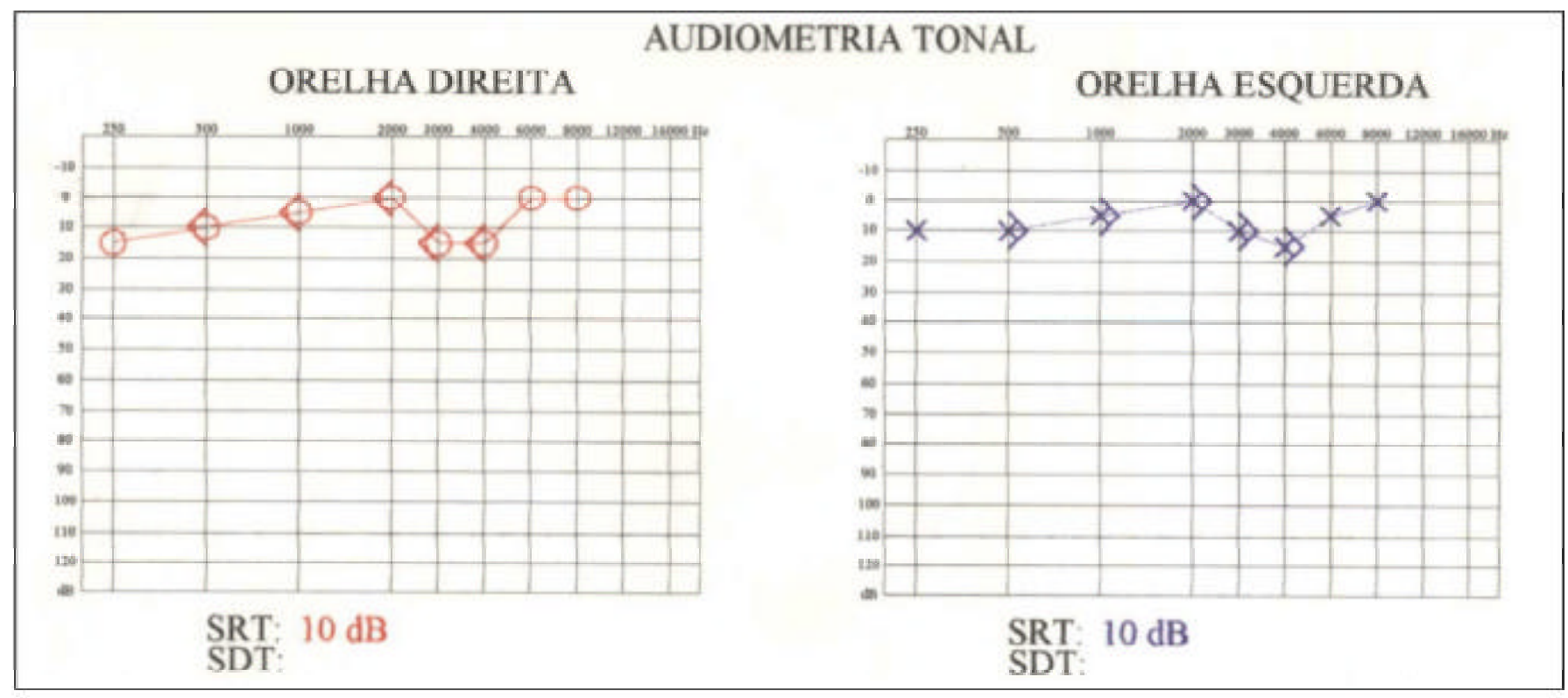

Figura 1b. Audiometria tonal realizada 10 dias após a primeira, com as mesmas condições técnicas, após melhora clínica da crise vertiginosa, mostrando limiares normais. A audiometria realizada após um ano encontra-se sem mudanças em relação a esta.

O paciente apresentado teve o diagnóstico de Doença de Ménière inicial em ouvido esquerdo firmado por otorrinolaringologista baseado em critérios clínicos otimizados pelo registro de flutuação auditiva na audiometria tonal. O hemograma mostrou hemácias - 5,36 (milhões $/ \mathrm{mm}^{3}$ ), HGB $-14,5 \mathrm{~g} / \mathrm{dl}$, HTC: $42,9 \%$ e VHS $-6 \mathrm{~mm} / \mathrm{h}$; leucócitos totais $-6,1$ milhôes $/ \mathrm{mm}^{3}$, segmentados $-65,8 \%$, eosinófilos $-1,3 \%$, basófilos - 0,1\%, linfócitos - 23\%, monócitos-9,8\%. Glicemia
$-85,1 \mathrm{mg} / \mathrm{dl}$, colesterol $-181 \mathrm{mg} / \mathrm{dl}$, triglicérides $-50 \mathrm{mg} /$ $\mathrm{dl}$, TSH $-2,8 \mathrm{UIU} / \mathrm{ml}$ e T4 livre $-1,5 \mu \mathrm{g} / \mathrm{ml}$.

Atualmente encontra-se assintomático com limiares tonais normais à audiometria (Figura 1b) e não apresentou novas crises, porém o exame de EOA da orelha esquerda mostra nítida assimetria quando comparada à orelha direita (Figuras 2 e 3), com alterações nas freqüências graves correspondentes àquelas relacionadas a flutuação 


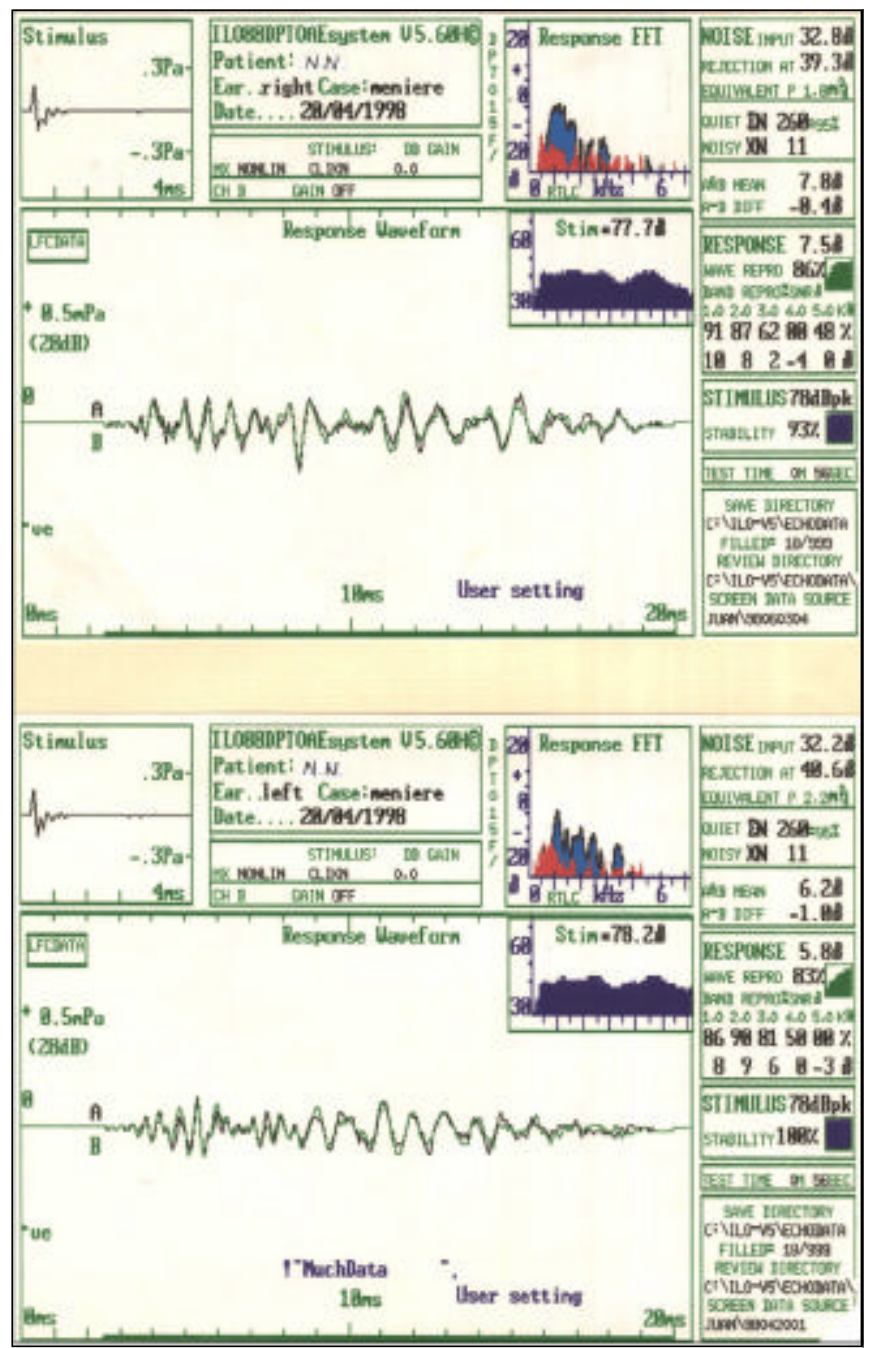

Figura 2. OEA-T em orelha esquerda e direita, mostrando baixa resposta em $7,5 \mathrm{~dB}$ em orelha direta e $5,8 \mathrm{~dB}$ em orelha esquerda. No gráfico FFT, o ruído de fundo é mostrado em vermelho e os ecos cocleares em azul.

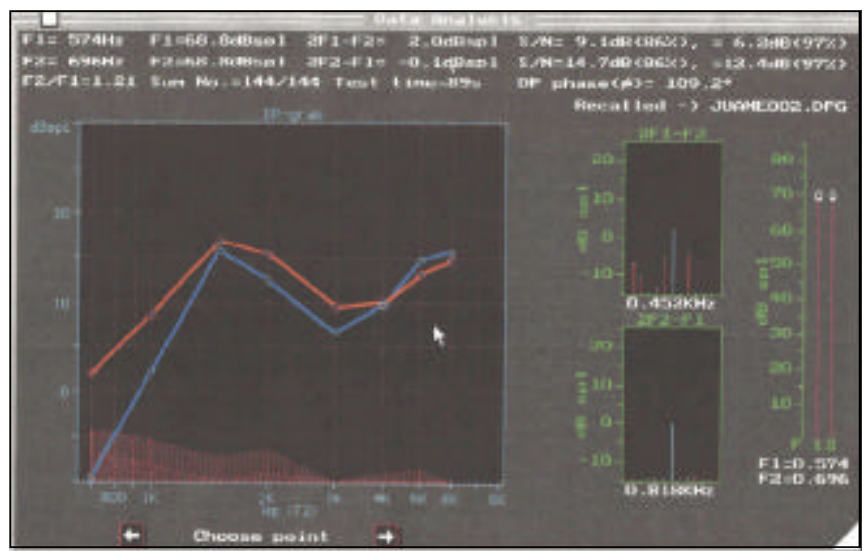

Figura 3. EOA-PD em orelha direita (vermelho) e orelha esquerda (azul), mostrando nítida assimetria nas freqüências baixas com ausência de respostas abaixo de $800 \mathrm{~Hz}$, evidenciando alteração cocleares nas freqüências correspondentes à flutuação auditiva registrada na audiometria tonal.

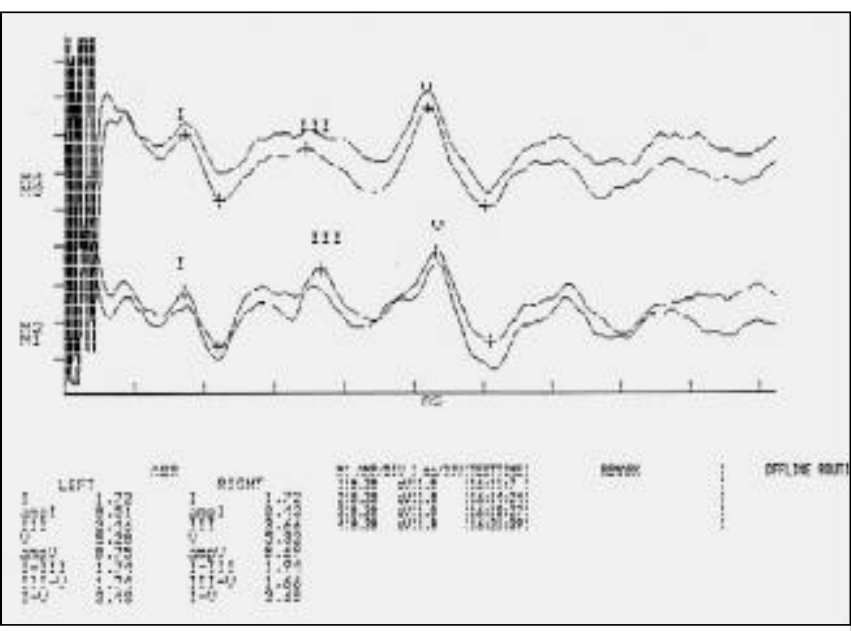

Figura 4. Traçado normal do BERA em orelhas direita e esquerda.

neurossensorial observada na audiometria tonal. O BERA obtido nas orelhas direita e esquerda mostrou latência e amplitudes normais (Figura 4).

Neste caso apresentado, o paciente é médico, tendo recusado submeter-se à realização de muitos exames subsidiários com sintomas provocativos ou desconfortáveis como as tonturas na eletronistagmografia ou a diarréia no teste do glicerol.

\section{COMENTÁRIOS}

O diagnóstico desta doença é essencialmente clínico, sendo a anamnese de capital importância juntamente com o exame otorrinolaringológico completo. Inúmeros exames subsidiários podem ser solicitados por ocasião da suspeita clínica de Doença de Ménière, porém nenhum deles pode dar um diagnóstico com certeza, sendo o conjunto sintomatológico aliado à evolução clínica a melhor forma de acompanhar a evolução da doença (Lopes Filho, 1994).

Os critérios para diagnóstico da doença de Ménière segundo Harris e Probst (1992) são: perda auditiva unilateral idiopática observada na audiometria, vertigem e zumbidos episódicos, sem anormalidades retrococleares nos testes objetivos; sem alterações condutivas observadas na impedanciometria ou nos testes de condução óssea; sem anormalidades neurológicas tanto na história clínica, como no exame físico e laboratorial. Estes critérios são otimizados por: audiometria com curva ascendente em freqüências baixas, que com o evoluir da doença atinge também outras freqüências; perda auditiva transitória ou intermitente documentada pela audiometria repetida; zumbido contínuo; piora da perda auditiva ou do zumbido associado à exacerbação da tontura; sensação de plenitude em orelha acometida ou nas duas orelhas. Nem sempre todos os critérios estão presentes, mas a associação de dois ou mais critérios podem reforçar a suspeita. 
Pacientes com a Doença de Ménière apresentam sintomas relacionados ao envolvimento dos sistemas vestibular e auditivo. Embora várias teorias tenham sido propostas para explicar as mudanças de sensitividade nesta doença, as alterações cocleares responsáveis ainda não foram determinadas definitivamente. A causa e patogênese da Doença de Méniére também é controversa e não definida. Na maioria das vezes o agente etiológico da doença não é identificado e pesquisas mais recentes tem atribuído a doença a mecanismos inflamatórios, multifatoriais e imuno mediados (Ruckenstein, 1999). O vírus Herpes simplex tipo I e o enterovírus têm sido responsabilizados por um mecanismo de gatilho na formação deste tipo de resposta auto imune do labirinto (Ruckenstein, 1999). Alergia alimentar e inalatória também tem sido largamente comentadas como fatores etiolgógicos desta doença e o tratamento desta condição pode resultar em melhora da doença de Méniére (Bryan, 1972).

A teoria dominante nas pesquisas sobre a Doença de Ménière é que ela é causada pelo aumento de pressão devido ao acúmulo de endolinfa. Esta condição pode ser criada experimentalmente em animais pela obstrução do saco endolinfático, que geralmente ocasiona hidropisia endolinfática, com resultados similares aos encontrados em seres humanos. Entretanto, os mecanismos subjacentes às alterações de sensitividade encontradas experimentalmente também ainda não estão claros (Harris e Probst, 1992).

Alterações rápidas de sensitividade em freqüências baixas ocorrem nos primeiros dias da instalação da hidropisia em cobaias, com alterações dos limiares de EOA nas freqüências correspondentes à diminuição de sensitividade. Desde que as células ciliadas não estejam destruídas durante os primeiros estágios da doença, os autores supõem que isto ocorra devido a alterações do micromecanismo tanto hidromecânico como biomecânico que afeta a transmissão do estímulo pela célula ciliada externa do órgão de Corti. É provável que muitos fatores sejam responsáveis pelos complexos mecanismos causadores da perda auditiva encontrada na Doença de Ménière. Apesar de se saber que o aumento de pressão endolinfática atua direta ou indiretamente sobre a célula ciliada externa, ainda é difícil correlacionar os achados experimentais realizados em animais com os sintomas encontrados em seres humanos (Horner e Cazals, 1989).

Uma pequena diminuição de células ciliadas externas restritas à região do ápice da cóclea pode ser verificada experimentalmente após aproximadamente dois meses de hidropisia e podem não justificar a diminuição auditiva observada. Um quadro anatomopatológico que apresenta uma excelente correlação com a perda auditiva em freqüências baixas é a atrofia seletiva dos estereocílios curtos e médios nesta região (Horner e Cazals, 1989).

O paciente estudado neste trabalho apresentou um quadro diagnosticado como sendo típico de Doença de Ménière em fase inicial, conforme descrito experimental- mente em cobaias, com surdez flutuante nas freqüências baixas na orelha esquerda comprovado por audiometria tonal, com recuperação após 10 dias. Os exames foram novamente realizados após um ano (audiometria tonal e IRF),e mostraram-se normais com melhora do limiar aéreo-ósseo em $30 \mathrm{~dB}$ na frequência de $125 \mathrm{~Hz}$, em relação a primeira audiometria. As respostas de EOA-PD mostraram-se diminuídas nas freqüências correspondentes à flutuação auditiva por provável alteração do micromecanismo hidrodinâmico e biomecânico conforme descrito anteriormente por Horner e Cazals (1989) e o BERA foi normal.

No caso deste paciente, as alterações encontradas na emissão otoacústica na orelha esquerda, e ainda não presentes na audiometria tonal e BERA, podem significar alterações nos estereocílios cocleares, sem morte das CCE da região apical conforme demonstrado experimentalmente em cobaias.

Uma questão que necessita ser formulada seria: o que protege a região basal da cóclea das alterações de limiares na hidropisia inicial enquanto as espiras apicais são atingidas? Tentando responder a esta questão, Horner (1990), argumentou que as patologias da região superior da cóclea podem ser favorecidas pelo maior tamanho dos estereocilios das CCE que aumentam progressivamente até o ápice. Esta alteração pode ocorrer devido à quebra das pontes interciliares. A presença da hidropisia dentro do espaço endolinfático pode forçar a membrana basilar para baixo ou a membrana tectorial para cima, introduzindo tensão e quebrando as pontes de ligação interciliares. Um segundo mecanismo que deve ser valorizado para explicar estas alterações é o mecanismo de feedback eferente que pode controlar e proteger seletivamente a espira basal da cóclea, onde terminam a maioria das fibras cruzadas mediais (Horner, 1990).

Apesar de existirem vários trabalhos mostrando que a cóclea pode ser comprometida na fase inicial da Doença de Ménière, sem que haja ainda um comprometimento das CCE na cobaia, isto ainda não havia sido correlacionado ás alterações de sensitividade auditiva encontradas em seres humanos. Acreditamos que isto se deva a vários motivos, entre eles o fato do diagnóstico clínico da Doença de Ménière ser sempre polêmico, das condutas médicas variarem de paciente para paciente, e, também, do fato da dificuldade maior para se firmar um diagnóstico na fase inicial da doença. Este trabalho é o primeiro a mostrar a Doença de Ménière documentada em fase inicial em humanos correlacionada a achados experimentais e à sensitividade da audiometria tonal e OEA. Um maior número de indivíduos precisa ser pesquisado para a confirmação desses dados no futuro, pois uma vez que isso ocorra, a EOA pode vir a se tornar um exame extremamente importante no seguimento dos pacientes com hidropisia endolinfática.

O paciente apresentado neste trabalho apresentou um quadro diagnosticado como sendo típico de doença do Ménière inicial com surdez flutuante em graves no ouvido 
esquerdo comprovado por audiometria tonal, com remissão após 10 dias. A audiometria tonal realizada após um ano, mostrou-se normal. A EOA mostrou-se alterada nas freqüências correspondentes a flutuação auditiva observada em ouvido esquerdo. Segundo trabalhos experimentais estas alterações não estão relacionadas à perda de CCE no ápice coclear, sendo que suas causas ainda não são muito claras podendo ser atribuídas às alterações do micromecanismo hidrodinâmico e biomecânico coclear, por alterações das pontes interciliares devido a distenção de membranas e células dentro do ducto coclear (Horner e Cazals, 1989).

\section{REFERÊNCIASBIBUOGRÁFICAS}

1. Bryan WTK, Bryan MP. Clinical examples of resolution of some idiopathic and other chronic disease by careful allergic management. Laringoscope 1972;82:1231-8.

2. Carnicelli MVF. O uso das emissões otoacústicas no diagnóstico e prevenção da perda auditiva induzida por ruído (PAIR). In: Nudelmann AA, Costa EA. Seligman J, Ibañez RN. PAIR. Porto Alegre (RS): Editora Bagagem Comunicação Ltda.; 1997. p. 237-45.
3. Harris FP, Probst R. Transiently evoked emissions in patients with Ménière disease. Acta Otolaryngol (Stockh) 1992;112:36-44.

4. Horner CK. Hypersensivity of hydropic ears, at frequencies with normal thresholds, to temporary threshold shifts. Hearing Research 1990;48:281-6.

5. Horner CK. Distortion products in early stage experimental hydrops in the guinea pig. Hearing Research 1989 (4-3):71-80.

6. Isaac ML, Aquino AMCM. Audiometria Eletrofisiológica. In: Sih T. Otorrinolaringologia Pediátrica. Rio de Janeiro: Revinter; 1998. cap. 41 p. 214-6.

7. Kenip DY, Bray P, Alexander L, Brown AM. Acoustic Emission Cochleography. Pratical aspects. Scand Audiol Suppl 1986;25:7195.

8. Lopes Filho O et al. Tratado de Fonoaudiologia. São Paulo: Editora Roca; 1997. p. 222-37.

9. Oliveira JAA. Fisiologia clínica da audição - cóclea ativa. In: Nudelmann AA, Costa EA, Seligman J, Raul NI. PAIR: Perda auditiva induzida por ruído. Porto Alegre (RS): Ed. Bagagem Com. Ltda.; 1997. p. 109-10.

10. Ruckenstein MJ. Immunologic aspects of Ménière disease. American Journal of Otolaryngology 1999;20(3):161-5. 